\title{
Comparison of Clinical and Demographic Features of FMF with Sacroiliitis Patients with FMF and Axial Spondyloarthritis Patients
} Vergleich klinischer und demografischer Besonderheiten zwischen Patienten mit FMF-assoziierter Sacroiliitis und Patienten mit FMF und axialer Spondylarthrose

Authors

Esra Dilşat Bayrak ${ }^{1}$, Sukran Erten², Orhan Kucuksahin ${ }^{3}$, Osman Ersoy $^{4}$

Affiliations

1 Rheumatology, Izmir Bozyaka Egitim ve Arastirma Hastanesi, İzmir Bozyaka Eah, İzmir

2 Rheumatology, Ankara, Yildirim Beyazit University Faculty of Medicine

3 Rheumatology, Ankara, Ankara Ataturk Egitim ve Arastirma Hastanesi

4 Gastroenterology, Ankara, Yildirim Beyazit University Faculty of Medicine

Key words

FMF with sacroiliitis, axial SpA, FMF, MEFV, HLA B27

Schlüsselwörter

FMF mit Sakroiliitis, axialem SpA, FMF, MEFV, HLA B27

published online $\quad 15.10 .2020$

Bibliography

Akt Rheumatol 2021; 46: 291-296

DOI 10.1055/a-1252-2190

ISSN 0341-051X

(c) 2020. Thieme. All rights reserved.

Georg Thieme Verlag KG, Rüdigerstraße 14,

70469 Stuttgart, Germany

Correspondence

Dr. Esra Dilşat Bayrak

Rheumatology

Izmir Bozyaka Egitim ve Arastirma Hastanesi

İzmir Bozyaka Eah

34752 İzmir

Turkey

Tel.: 05052502523, Fax: 2322505050

drdilsat@hotmail.com

\section{ABSTRACT}

Objectives Familial Mediterranean fever (FMF) is the most common autoinflammatory disease, characterised by recurrent fever and serositis attacks lasting 1-3 days. Musculoskeletal involvement is the second most common manifestation in FMF patients. Sacroiliitis is another musculoskeletal involvement; as there is no spinal involvement, this is called FMF with sacroiliitis. This study was designed to investigate the clinical, demographic and genetic features of FMF in sacroiliitis patients and to compare them with axial SpA and FMF patients.

Materials and Methods Forty-two FMF with sacroiliitis patients, 100 axial SpA patients and 100 FMF patients were recruited, and their demographic characteristics were recorded. Evidence of sacroiliitis was confirmed by sacroiliac joint MRI, and patients were examined for arthritis and enthesitis. MEFV gene mutations, HLA B27 positivity and ESR and CRP results were compared.

Results In the FMF with sacroiliitis group, the M694V mutation was detected in $59.5 \%$ of patients. FMF with sacroiliitis patients were largely (83.3\%) negative for HLA B27. The frequency of enthesitis was similar between FMF with sacroiliitis and axial $S p A$, and the frequency of arthritis was higher in axial SpA patients. Inflammatory markers (ESR and CRP) were statistically higher in FMF with sacroiliitis patients compared with axial SpA and FMF patients.

Conclusion When all three groups were compared, the M694V mutation was more common, HLA B27 was largely negative and inflammatory markers were higher in the FMF with sacroiliitis group. FMF should be included in the differential diagnosis of sacroiliitis for managing treatment correctly and preventing complications.

\section{ZUSAMMENFASSUNG}

Ziele Familiäres Mittelmeerfieber ( FMF) ist die häufigste autoinflammatorische Erkrankung, die sich durch wiederholte, 1-3 Tage andauernde Fieber- und Serositisanfälle auszeichnet. Die muskuloskelettale Beteiligung ist die zweithäufigste Manifestation bei Patienten mit FMF. Eine weitere muskuloskelettale Beteiligung ist die Sacroiliitis und wird wegen fehlender Wirbelsäulenbeteiligung als FMF-assoziierte Sacroiliitis/Spondyloarthritis bezeichnet. Diese Studie wurde durchgeführt, um die klinischen, demografischen und genetischen Merkmale von FMF bei Sakroiliitis-Patienten zu untersuchen und mit axialen SpA- und FMF-Patienten zu vergleichen.

Materialen und Methoden 42 Sacroiliitis-Patienten mit FMF, 100 axiale SpA-Patienten und 100 FMF-Patienten wurden 
eingeschlossen und deren demographische Merkmale aufgezeichnet. Der Nachweis einer Sakroiliitis wurde durch MRT des Iliosakralgelenks bestätigt, und die Patienten wurden auf Arthritis und Enthesitis untersucht. MEFV-Genmutationen, HLA B27Positivität sowie ESR- und CRP-Ergebnisse wurden verglichen.

Ergebnisse In der FMF mit Sakroiliitis-Gruppe wurde die M694V-Mutation bei 59,5\% der Patienten nachgewiesen. Sacroiliitis-Patienten mit FMF waren überwiegend (83,3\%) negativ für HLA B27. Die Häufigkeit der Enthesitis war zwischen FMF mit Sakroiliitis und axialem SpA ähnlich, und die Häufigkeit von
Arthritis war bei Patienten mit axialem SpA höher. Die Entzündungsmarker (ESR undCRP) waren für Sacroiliitis-Patienten mit FMF im Vergleich zu Patienten mit axialer SpA und FMF statistisch höher.

Fazit Nach Vergleich dieser drei Gruppen trat die M694V-Mutation häufiger auf, HLA B27 war weitgehend negativ und die Entzündungsmarker waren in der Sacroiliitis-Gruppe mit FMF höher. Das FMF ist eine mögliche Differential diagnose der Sakroillitis und sollte als solche, bei entsprechendem Kontext, berücksichtigt werden.

\section{Introduction}

Familial Mediterranean fever (FMF) is a hereditary autoinflammatory syndrome characterised by sporadic, paroxysmal, self-limiting episodes of fever and serosal inflammation. The typical appearance of the disease is serositis and fever attacks lasting 1-3 days. The disease most frequently affects Jews, Armenians, Turks and Arabs.

In a study conducted in Turkey, it was shown that FMF prevalence is $1 / 1000$ [1]. MEFV gene mutations are responsible for the pathogenesis of this autosomal recessive disease. Although classic arthritis attacks are among the most common musculoskeletal manifestations, sacroiliitis is another musculoskeletal manifestation of the disease. Sacroiliitis is one of the distinguishing features of spondyloarthritis (SpA) but has been observed to increase in frequency in Turkish and Jewish FMF patients. Despite being described for the first time in the 1960s, FMF with sacroiliitis is difficult to diagnose in patients and often delayed. In a study from Turkey, it was shown that about $7 \%$ of FMF patients develop sacroiliitis [2]. Absence of vertebral involvement and the negativity of HLA-B27 are considered to be the main features of sacroiliitis associated with FMF [3]. It was also shown that the prevalence of the M694V mutation was higher in FMF with sacroiliitis patients $[4,5]$.

Although there are studies investigating the prevalence of FMF with sacroiliitis, to our knowledge there is no study comparing axial SpA and FMF patients with FMF with sacroiliitis patients; therefore, this study is designed to determine the clinical, demographic, genetic and inflammatory characteristics of FMF with sacroiliitis patients and to compare them with axial SpA and FMF patients.

\section{Materials and Methods}

This study was approved by the Yıldırım Beyazıt University Ankara Atatürk Education Research Hospital Ethics Committee. During the study, the guidelines of the World Medical Association Helsinki Declaration and Good Clinical Practice Guidelines were followed.

Forty-two FMF with sacroiliitis, 100 FMF and 100 axial SpA patients (total of 242 patients) that were admitted to Ankara Atatürk Training and Research Hospital between 01,06,2012 and 01,06,2014 were evaluated. Tel Hashomer criteria were used [7] for FMF diagnosis and ASAS axial SpA criteria were used for diagnosis of [8] for axial SpA. Demographic characteristics of the patients were recorded; patients were questioned for age, gender, disease duration, arthritis, enthesitis and used medication. Routine physical examination and musculoskeletal findings were recorded.
All patients with chronic inflammatory low back pain were studied for the presence of axial SpA. Inflammatory back pain was assessed according to the ASAS definition. Sacroiliac joint MRI had been performed in all cases with inflammatory back pain. MRI examination consisted of T1, T2 and STIR sequences. Active inflammatory lesions of sacroiliac joints with definite bone marrow oedema/osteitis in MRI were accepted as positive for sacroiliitis. Clinical and radiologic assessments were performed by one rheumatologist. Patients diagnosed with axial SpA in both FMF and axial SpA were examined for arthritis and enthesitis. Pain or tenderness in the enthesis regions ( $1^{\text {st }}$ costochondral, $7^{\text {th }}$ costochondral, posterior superior iliac spine, anterior superior iliac spine, iliac crest, proximal achilles and $5^{\text {th }}$ lumbar spinous process) were assessed using MASES (Maastricht AS Enthesitis Score) [9]. Forty-four joints were evaluated for peripheral arthritis; patients with one or more affected peripheral joints were reported as arthritis positive.

Results of MEFV gene mutations of FMF and FMF with sacroiliitis SpA patients and HLA B27 mutations of axial SpA patients and FMF with sacroiliitis patients were recorded. HLA B27 antigen expressions were studied in total genomic DNA isolated from peripheral blood samples using the polymerase chain reaction (PCR) method. MEFV gene mutations were investigated using PCR and a reverse hybridisation assay.

The drugs used by the patients were divided into 4 groups: colchicine, NSAID, DMARDs and biologic therapy.

Bath ankylosing spondylitis disease activity index (BASDAI) scores were measured to assess disease activity at baseline visits for FMF with sacroiliitis and axial SpA patients. The complete blood, biochemistry, erythrocyte sedimentation rate (ESR) and c-reactive protein (CRP) values observed during the patients' first visits were recorded. For FMF patients, ESR and CRP were measured during a non-attack period.

Survey inclusion criteria:

1 Over 18 years old

2 Volunteer to participate in the study

3 Agree to have FMF diagnosis according to Tel Hashomer criteria

4 Agree to have axial SpA diagnosis according to ASAS axial SpA citeria

5 Sacroiliitis in sacroiliac MRI for FMF with sacroiliitis and axial SpA patients

Patients with rheumatologic diseases other than FMF and axial SpA who have psoriasis, recurrent oral aphtous and genital ulcers, in- 
flammatory bowel diseases and amiloidosis were excluded. Athletes and postpartum women are also excluded to rule out false positives in sacroiliac MRI.

\section{Statistical Analysis}

The Statistical Package for Social Science (SPSS) 20.0 program was used to evaluate the results. Correlation analyses were performed using the Sperman correlation test. An ANOVA test was used to test the difference between age and disease duration between 3 groups. Variance homogeneity was shown using the Levene's test in terms of age among the groups. Non parametric data were compared with a chi-square test, and ESR and CRP were compared with a t-test. MEFV gene mutations were compared using a 2 proportion t-test.

\section{Results}

The study consisted of 42 FMF with sacroiliitis, 100 axial SpAand 100 FMF patients.

\section{FMF with Sacroiliitis Group}

The median age of the FMF with sacroiliitis group was 35.88 years. Twenty-nine patients (69\%) were female and 13 were male (13\%). Median disease duration was 7.5 years. Of the 42 patients, 40 had the MEFV gene mutation. Of these patients, 26 had the M694V gene mutation, 7 had the M680I and 7 had the E148Q mutation. HLA B27 was found negative in 35 patients ( $83.3 \%$ ); only 7 patients (16.7\%) tested positive. The median BASDAI score among FMF with sacroiliitis patients was 5.6. Clinical and demographic characteristics of the FMF with sacroiliitis group are displayed in $>$ Table $\mathbf{1}$.

The frequency of arthritis was $28.6 \%$ (12 patients) while the frequency of enthesitis was $35.7 \%$ (15 patients). None of the patients had spinal involvement.

In the FMF with sacroiliitis group, 13 patients (31\%) received biologic therapy (anti-TNF), 4 patients received colchicine + DMARD, 14 patients received colchicine + NSAID, 8 patients received colchicine + DMARD + NSAID and only 3 took colchicine only.

\section{Comparison of Groups}

The median age of the FMF with sacroiliitis group was $35.88 \pm 10.367$ years ( 29 female, 13 male), $46.72 \pm 1.09$ years in the axial SpA group (81 female, 19 male) and $37.04 \pm 12.33$ years in the FMF group (65 female, 35 male). A significant difference was found when evaluating gender frequencies among the groups; in the axial SpA group, the female ratio was about 4 times higher than the male ratio.

The number of patients diagnosed under age 30 was 14 in the FMF with sacroiliitis group, 8 in the axial SpA group and 34 in the FMF group. FMF with sacroiliitis and FMF patients were statistically much younger than axial SpA patients ( $p: 0,001)$. Also it was observed that sacroiliitis symptoms were developed after FMF diagnosis in all FMF with sacroiliitis patients.
Median disease duration was $7.5 \pm 5.3$ years in the FMF with sacroiliitis group, $4.9 \pm 4.3$ years in the axial SpA group and $5.16 \pm 5.5$ years in the FMF group. Disease duration in the FMF with sacroiliitis group was longer than the axial SpA and FMF groups ( $p: 0,017$ and $p: 0.02$ respectively). Baseline characteristics of all 3 groups are displayed in $>$ Table 2.

Patients were evaluated for arthritis and enthesitis. Arthritis was observed in 12 patients (28.6\%) in the FMF with sacroiliitis group and 59 patients (59\%) in the axial SpA group. The difference was statistically significant $(p=0.001)$. Frequency of enthesitis was $35.7 \%$ in the FMF with sacroiliitis group and $39 \%$ in the axial SpA group; no statistical difference was found $(p=0.713)$.

HLA B27 positivity was $16 \%$ in the FMF with sacroiliitis group and $27 \%$ in the axial SpA group. No difference was showed between the 2 groups ( $p=0.178$ ). Median value of BASDAI was 5.6 in the FMF with sacroiliitis group and 5.7 in the axial SpA group. There was no difference between the 2 groups ( $p=0.919)$.

The median CRP value was 19.1 in the FMF with sacroiliitis group, 2.5 in the axial SpA group and 3.3 in the FMF group. In the FMF with sacroiliitis group, CRP and ESH values were much higher than the FMF and axial SpA groups $(p<0.001$ and $p<0.000$, respectively).

25 patients in the FMF with sacroiliitis group (59.5\%) and 46 patients (46\%) in the FMF group had M694V mutation. The 2 groups showed no difference in terms of MEFV mutation gene distribution $(p=0.140)$

\section{Discussion}

Sacroiliitis is one of the distinguishing features of SpA and has been observed to increase in frequency in Turkish and Jewish FMF patients. In the absence of ankylosing spondylitis features, the disease is referred to as FMF with sacroiliitis. Sacroiliitis develops without vertebral involvement in FMF with sacroiliitis patients and has been suggested for use in the differentiation from classical axial SpA. When we look at the data about the frequency of the disease, we encounter different results. Kaşifoglu and colleagues reported $7 \%$ of patients with FMF had sacroiliitis [2]. In a study conducted by Cefle et al. in $503 \mathrm{FMF}$ patients, the incidence of sacroiliitis was $10.5 \%$ [10]. Langevitz et al. reported $0.4 \%$ frequency of sacroiliitis in a large cohort study involving 3000 FMF patients [3]. Differences between studies can be explained by variabilities of the patient population and differences in the radiological methods used to detect sacroiliitis. In Langevitz et al., sacroiliitis was not detected by MRI. Consequently, some cases may not be diagnosed, especially in early phases of the disease. In this study, MRI was used for all FMF patients for detection of sacroliitis.

In the present study, M694V gene mutation is the predominant type in both groups, and no statistically significant difference was found between them. M694V predominance is compatible with the previous studies. Phenotype-genotype correlation has not yet been clarified; however, in recent studies, M694V gene mutation has been associated with the early onset of the disease, an increase in arthritis frequency and the high incidence of amyloidosis $[11,12]$. Researchers also showed that MEFV gene mutations may facilitate the development of SpA as well as changes in response to inflammatory diseases. Three different studies from Turkey show- 
- Table 1 Clinical, laboratory and genetic findings of FMF with sacroiliitis patients.

\begin{tabular}{|c|c|c|c|c|c|c|c|c|c|c|c|}
\hline patient & gender & age & MEFV & $\begin{array}{l}\text { Disease } \\
\text { duration }\end{array}$ & $\begin{array}{l}\text { BAS- } \\
\text { DAI }\end{array}$ & $\begin{array}{l}\text { pati- } \\
\text { ent }\end{array}$ & gender & age & MEFV & $\begin{array}{l}\text { Disease } \\
\text { duration }\end{array}$ & BASDAI \\
\hline 1 & Female & 43 & E148Q/E148Q & 3 & 5.6 & 22 & Female & 64 & E148Q/- & 2 & 1.8 \\
\hline 2 & Female & 26 & M680I/- & 2 & - & 23 & Male & 37 & M680I/V726A & 5 & 2.8 \\
\hline 3 & Male & 50 & M694V/- & 4 & - & 24 & Female & 44 & M680I/- & 2 & 6.3 \\
\hline 4 & Female & 49 & E148Q/- & 6 & 4.2 & 25 & Male & 26 & M694V/- & 5 & 2.4 \\
\hline 5 & Female & 39 & E148Q/- & 4 & 7.5 & 26 & Male & 28 & M694V/- & 9 & 7.8 \\
\hline 6 & Female & 38 & M690I/- & 5 & 8.1 & 27 & Male & 15 & M694V/- & 9 & 7.8 \\
\hline 7 & Female & 48 & M694V/- & 2 & 6.7 & 28 & Male & 27 & M694V/M694V & 3 & 6.5 \\
\hline 8 & Female & 33 & M694V/- & 2 & 3 & 29 & Female & 42 & M694V/M694V & 10 & 6.5 \\
\hline 9 & Female & 21 & M680I/- & 3 & 2.5 & 30 & Male & 20 & M680I/M680I & 7 & 6.4 \\
\hline 10 & Female & 42 & M680I/- & 9 & 5.1 & 31 & Female & 28 & M694V/M694V & 10 & 6.7 \\
\hline 11 & Female & 28 & M694V/E148Q & 3 & 4.5 & 32 & Male & 37 & M694V/- & 20 & 7.8 \\
\hline 12 & Female & 52 & M694V/- & 4 & 8.2 & 33 & Female & 34 & M694V/M694V & 7 & 6.7 \\
\hline 13 & Female & 39 & E148Q/- & 6 & 10 & 34 & Male & 28 & M694V/V726A & 12 & 6.7 \\
\hline 14 & Male & 19 & M694V/- & 12 & 4.5 & 35 & Female & 57 & M694V/M694V & 2 & 4.5 \\
\hline 15 & Female & 31 & E148Q/- & 5 & 3.6 & 36 & Female & 34 & M694V/- & 2 & 4 \\
\hline 16 & Female & 45 & M694V/- & 5 & 5.6 & 37 & Female & 34 & M694V/M680I & 15 & 7.6 \\
\hline 17 & Female & 34 & M694V/M680I & 15 & 2 & 38 & Female & 39 & M694V/M694V & 15 & 5.6 \\
\hline 18 & Female & 43 & M694V/- & 7 & 1.8 & 39 & Male & 28 & M694V/- & 8 & 7.4 \\
\hline 19 & Female & 29 & M694V/V726A & 15 & 4.2 & 40 & Male & 35 & - & 8 & 8.4 \\
\hline 20 & Male & 38 & M694V/- & 20 & 7 & 41 & Female & 31 & - & 22 & 8.8 \\
\hline 21 & Female & 44 & E148Q/- & 3 & 4.3 & 42 & female & 28 & M694V/M680I & 7 & - \\
\hline
\end{tabular}

- Table 2 Comparison of groups with FMF with sacroiliitis, axial SpA and FMF patients.

\begin{tabular}{|c|c|c|c|c|c|}
\hline \multirow[b]{2}{*}{ Gender (n) } & \multirow[b]{2}{*}{ Female/male } & \multirow{2}{*}{$\begin{array}{l}\text { FMF with sacroiliitis }(n=42) \\
28 / 13\end{array}$} & \multirow{2}{*}{$\begin{array}{l}\text { Axial SpA }(n=100) \\
81 / 19\end{array}$} & \multirow{2}{*}{$\begin{array}{l}\text { FMF }(n=100) \\
65 / 35\end{array}$} & \multirow{2}{*}{$\begin{array}{l}\text { P value } \\
0.04\end{array}$} \\
\hline & & & & & \\
\hline \multirow{3}{*}{ Age (median) } & $15-30$ & 14 & 8 & 34 & \multirow{3}{*}{0.01} \\
\hline & $30-60$ & 27 & 80 & 63 & \\
\hline & $>60$ & 1 & 12 & 3 & \\
\hline \multicolumn{2}{|c|}{ Disease duration (median) (years) } & 7.5 & 4.91 & 5.16 & 0.02 \\
\hline \multicolumn{2}{|c|}{ BASDAI (median) } & 5.66 & 5.7 & & 0.919 \\
\hline \multirow{4}{*}{$\operatorname{MEFV}(n)$} & M694V & 26 & & 46 & \\
\hline & M680I & 7 & & 18 & \\
\hline & E148Q & 7 & & 16 & \\
\hline & other & 2 & & 20 & \\
\hline \multicolumn{2}{|l|}{ M694V/others } & $25 / 17$ & & $46 / 54$ & 0.140 \\
\hline \multicolumn{2}{|c|}{ HLA B27 positivity n (\%) } & 7 (16.7) & $27(27)$ & $7(16.7)$ & 0.178 \\
\hline \multicolumn{2}{|l|}{ Arthritis n (\%) } & $12(28.6)$ & $59(59)$ & $12(28.6)$ & 0.001 \\
\hline \multicolumn{2}{|l|}{ Enthesitis n (\%) } & $15(35.7)$ & $39(39)$ & $15(35.7)$ & 0.713 \\
\hline \multicolumn{2}{|c|}{ ESR mm/h (median) } & 40.02 & 26.43 & 21.65 & 0.021 \\
\hline \multicolumn{2}{|c|}{ CRP mg/L (median) } & 19.1 & 2.5 & 3.3 & 0.001 \\
\hline
\end{tabular}


ed that MEFV gene mutations, mostly M694V mutation, is significantly higher in Ankylosing Spondylitis patients than control groups [13-15].

E148Q mutation is one of the common mutations among patients with FMF, with $3.5 \%$ allele frequency and a carrier frequency of $12 \%$ in the healthy Turkish population [16]. Another population based field study from Turkey revealed that $14.8 \%$ of 500 normal healthy individuals had MEFV mutations being the most common E148Q (4.8\%) and the second M694V (3.2\%) [17]. Because carrier frequencies were far higher among healthy carriers than among patients with FMF, it has been proposed that E148Q is a polymorphism, not a disease causing mutation [18-20]. But 2 study from Turkey showed that most patients who had E148Q mutation are symptomatic and colchicine treatment is required in these patients $[21,22]$. This study also showed that E148Q mutation was the third most common mutation and causes disease development.

In our axial spondyloarthritis group most of the patients were non-radiographic ax-SpA (nr-axSpA), only \% 8 meet the Modified New York criteria. We know from large cohort studies that the frequency of nr-axSpA is much higher than that of AS. According to the previous studies the proportion of patients identified as having $\mathrm{nr}$-axSpA among newly diagnosed ax-SpA patients ranged from 23 to $80 \%$ [23-25]. However, the probability of these patients to be diagnosed is much lower than those of AS patients. We think that the reason for the higher rate of $\mathrm{nr}$-axSpA patients in our study may be the use of MRI for diagnosis in all patients.

We also saw that only $8 \%$ of axial Spa patients were diagnosed under age 30 in our study. Some patients were diagnosed at an advanced age. When we look at these patients all of them were nraxSpA patients and especially female $\mathrm{nr}$-axSpA patients have been followed up with a diagnosis of fibromiyalgia for many years. These findings suggest that there is a considerable delay in the diagnosis of women with nr-axSpA.

In the FMF with sacroiliitis group, HLA B27 was found to be negative in great proportion. The absence of HLA B27 suggests that different mechanisms are involved in the development of sacroiliitis in FMF patients than ankylosing spondylitis patients. These results show that the use of HLA B27 in distinction between these two diseases is not beneficial; however, if patients with FMF and sacroiliitis are found to be HLA B27 positive with findings such as spinal ankylosis, bamboo spine and uveitis, these patients should be described as FMF and AS. Akar et al.observed a frequency of $7.5 \%$ for AS and $8.9 \%$ for axial SpA in FMF patients [6].

Also, HLA B27 positivity was found to be low in axial SpA group. As we mentioned above the vast majority of our patients were $\mathrm{nr}$ axSpA. Recent studies have shown that HLA B27 positivity is much more lower in nr-axSpA patients than AS. Also HLA B27 positivity rates in $\mathrm{nr}$-axSpA disease in different ethnic groups are highly variable. Omair et all showed that HLA B27 positivity was found to be $25,9 \%$ in nr-axSpA patients in Saudi Arabia [26]. Another study conducted in Sri Lanka, the HLA B27positivity in Spondyloarthritis patients was found to be $22.8 \%$ [27]. In the Colombian population HLA B27 positivity was reported as $12.1 \%$ in patients with signs of Spondyloarthritis but also it was said that most of the patients had peripheral disease [28]. Also it was seen that HLA positivity in patients with AS in Turkey is lower than the European population. Kasapoglu et all showed that HLA B27 positivity was $70 \%$ in AS pa- tients in Turkey, which is expected to be much lower in nr-axSpA population [29].

When groups were compared in terms of gender, female predominance was observed in all three. The female ratio in the SpA group is roughly 4 times that of the male ratio and twice that of the other 2 groups. In the FMF with sacroiliitis group, the proportion of males seems to be relatively higher than that of the SpA group. In the Langevitz study, 9 of the 11 patients were male, and patients in Kaşifoğlu's study were predominantly male [2,3]. Our findings are consistent with the study of Akar et al. Also in our study female predominance was quite prominent in axial SpA patients. Many different studies have shown that the majority of nr-axSpA patients are women. In a study conducted by Kiltz et all, patients with nraxSpA were characterized by the low proportion of male patients (31.8\%) [30]. Also we saw the same female predominance in big cohort studies. Also women may be admitted to the hospital more frequently with these complaints and that may be the reason of the high frequency of women.

In all 3 groups, inflammatory parameters (CRP and ESR) associated with disease activity were measured. Measurements are taken in non-attack period in FMF and FMF with sacroiliitis patients. The ESR and CRP values for the FMF with sacroiliitis group were found to be statistically higher than the axial SpA and FMF groups. Higher levels of inflammatory markers in the FMF with sacroiliitis group are expected suggests more severe inflammation in FMF with sacroiliitis patients.

It is still a matter of debate whether the MEFV gene mutation is a triggering factor for SpA or sacroiliitis is a feature of FMF. Diagnosis of FMF in patients presented with sacroiliitis is important since early diagnosis with colchicine treatment will prevent amyloidosis. In these patients especially with unexplained high inflammatory markers, presence of another disease like FMF should be kept in the mind.

To the best of our knowledge, this is the first study comparing FMF with sacroiliitis with axial SpA and FMF patients.

\section{Conflict of Interest}

The authors declare that they have no conflict of interest.

\section{References}

[1] Dinc A, Pay S, Turan M et al. Prevalence of familial Mediterranean fever in young Turkish men [abstract]. Clin Exp Rheumatol 2000; 18: 292

[2] Kaşifoğlu T, Calişir C, Cansu DU et al. The frequency of sacroiliitis in familial Mediterranean fever and the role of HLA-B27 and MEFV mutations in the development of sacroiliitis. Clin Rheumatol 2009; 28: 41

[3] Langevitz P, Livneh A, Zemer D et al. Seronegative spondyloarthropathy in familial Mediterranean fever. Semin Arthritis Rheum 1997; 27 : $67-72$

[4] Yiğit S, Bağcı H, Ozkaya O et al. MEFV mutations in patients with familial Mediterranean fever in the Black Sea region of Turkey. J Rheumatol 2008; 35: 106-113

[5] Olgun A, Akman S, Kurt I et al. MEFV mutations in familial Mediterranean fever: association of M694V homozygosity with arthritis. Rheumatol Int 2005; 25: 255-259 
[6] Akar S, Soysal O, Yuksel F et al. High prevalence of axial spondyloarthritis in patients with familial Mediteranean fever, and a greater allelic frequency of M694V in familial Mediteranean fever patients with radiograpic sacroiliitis. Arthritis Rheum 2010; 62: S278

[7] Livneh A, Langevitz P, Zemer D et al. Criteria for the diagnosis of familial Mediterranean fever. Arthritis Rheum1997 40: 1879-1885

[8] Sieper J, Rudwaleit M, Baraliakos X. The Assessment of SpondyloArthritis international Society (ASAS) handbook: a guide to assess spondyloarthritis. Ann Rheum Dis 2009; 68: ii1-ii44

[9] Heuft-Dorenbosch L, Spoorenberg A, vanTubergen A et al. Assessment of enthesitis in ankylosing spondylitis. Ann Rheum Dis 2003; 62: $127-132$

[10] Cefle A, Kamali S, Sayarlioglu M et al. A comparison of clinical findings of familial Mediterranean fever patients with and without amyloidosis. Rheumatol Int 2005; 25: 442-446

[11] Tunca M, Akar S, Onen F et al. Familial Mediterrenean Fever (FMF) in Turkey: results of a nationwide multicenter study. Medicine (Baltimore) 2005; 84: 1-11

[12] Brik R, Shinawi M, Kepten I et al. Familial Mediterranean fever: clinical and genetic characterization in a mixed pediatric population of Jewish and Arab patients. Pediatrics 1999; 103: e70

[13] Maras Y, Akdogan A, Kısacık B. MEFV mutation frequency and effect on disease severity in Ankylosing Spondylitis. Turk J Med Sci 2014; 44: 203-207

[14] Cosan F, Ustek D, Oku B et al. Association of familial Mediterranean fever-related MEFV variations with ankylosing spondylitis. Arthritis Rheum 2010; 62: 3232-3236

[15] Akkoc N, Sari I, Akar S et al. Increased prevalence of M694V in patients with ankylosing spondylitis: additional evidence for a link with familial mediterranean fever. Arthritis Rheum 2010; 62: 3059-3063

[16] Yilmaz E, Ozen S, Balci B et al. Mutation frequency of Familial Mediterranean Fever and evidence for a high carrier rate in theTurkish population. Eur J Hum Genet 2001; 9: 553-555

[17] Soylemezoglu O, Kandur Y, Gonen S et al. Familial Mediterranean fever gene mutation frequencies in a sample Turkish population. Clin Exp Rheumatol 2016; 34: 97-100

[18] Ben-Chetrit E, Lerer I, Malamud E et al. The E148Q mutation in the MEFV gene: is it a disease causing mutation or a sequence variant? Hum Mutat 2000; 15: 285-286

[19] Stoffman N, Magal N, Shohat T et al. Higher than expected carrier rates for familial Mediterranean fever in various Jewish ethnic groups. Eur J Hum Genet 2000; 8: 307
[20] Askentijevich I, Torosyan Y, Samuels 」 et al. Mutational and haplotype studies in familial Mediterranean fever reveal new ancestral relationships and evidence for a high carrier frequency with reduced penetrance in the Ashkenazi Jewish population. Am J Hum Genet 1999; 64: 949-962

[21] Topaloglu R, Ozaltın F. E148Q is a disease-causing MEFV mutation: A phenotypic evaluation in patients with familial mediterranean fever. Ann Rheum Dis 2005; 64: 750-752

[22] Aydın F, Çakar N. Clinical features and disease severity of Turkish FMF children carrying E148Q mutation. J ClinLab Anal 2019; 33: e22852

[23] Dougados M, d'Agostino MA, Benessiano J et al. The DESIR cohort: a 10-year follow-up of early inflammatory back pain in France: study design and baseline characteristics of the 708 recruited patients. Joint Bone Spine 2011; 78: pp 598-603

[24] van den Berg R, de Hooge M, vanGaalen F et al. Percentage of patients with spondyloarthritis in patients referred because of chronic back pain and performance of classification criteria: experience from the Spondyloarthritis Caught Early (SPACE) cohort. Rheumatology (Oxford) 2013; 52: pp 1492-1499

[25] Sieper J, Srinivasan S, Zamani O.et. al. Comparison of two referral strategies for diagnosis of axial spondyloarthritis: the Recognising and Diagnosing Ankylosing Spondylitis Reliably (RADAR) study. Ann Rheum Dis 2013; 72: pp 1621-1627

[26] Omair MA, AlDuraibi FK, Bedaiwi MK et al. Prevalence of HLA-B27 in the general population and in patients with axial spondyloarthritis in Saudi Arabia. Clin Rheumatol 2017; 36: 1537-1543

[27] Kidnapillai S, Sirisena ND, Dissanayake VHW. HLA-B27 allele frequency in Sri Lankan patients with spondyloarthritides. Ceylon Medical Journal 2016; 61: pp 71-73

[28] Romero-Sanchez Consuelo, Chila-Moreno Lorena et al. The Frequency of HLA-B27 in a Colombian Population with Signs of Spondyloarthritis Curr Rheumatol Rev 2018; 14: 246-250

[29] Gunal Esen Kasapoglu, Sarvan Fatma Oguz et al. Low Frequency of HLA-B27 in Ankylosing Spondylitis Patients From Turkey. Eur J Rheumatol 2017; 4: 268-271

[30] Kiltz U, Baraliakos X, Karakostas P.et. al. Do patients with non-radiographic axial spondyloarthritis differ from patients with ankylosing spondylitis? Arthritis Care Res (Hoboken) 2012; 64: pp 1415-1422 